\title{
The SCOPE OF THe Place OF SAFETy WARRANTS UNDER THE CHILDREN, YOUNG PERSONS, AND THEIR FAMILIES ACT 1989
}

\author{
Paul Beverley*
}

The Children, Young Persons, and Their Families Act 1989 ("CYPF Act") recognises that the interests of a child will be generally best served within the family unit. This recognition is subject to the qualification that a child should be removed from that unit whenever there is an unacceptable risk of harm to that child. This analysis will consider one mechanism provided by the Act to facilitate such removal, and the effect of the Court of Appeal decision in $\mathrm{R} \mathrm{v} \mathrm{Kahu.}{ }^{1}$

\section{THE PLACE OF SAFETY WARRANT}

Section 39 of the CYPF Act provides for the removal of children and young persons from their families in situations of serious risk. The section creates the place of safety warrant ("POS") which may be issued on the ex parte application of a social worker or member of the police:

39. Place of safety warrants - (1) Any District Court Judge or, if no District Court Judge is available, any Justice or any Registrar (not being a member of the Police), who on application in writing made on oath, is satisfied that there are reasonable grounds for suspecting that a child or young person is suffering, or is likely to suffer, ill-treatment, neglect, deprivation, abuse, or harm may issue a warrant authorising any member of the Police or a Social Worker, either by name or generally, to search for the child or young person....

* Lecturer in Law, Nelson Polytechnic. This article is based on a research paper which was completed by the writer as partial fulfilment of the requirements of the degree of LLM at Victoria University of Wellington. During that process a number of social workers from the New Zealand Children and Young Persons Service were interviewed. This article includes comments made by those persons. The writer expresses appreciation to the Service and to the persons interviewed for their assistance. 
Part II of the Act creates two other removal powers in addition to the POS warrant. Section 42 empowers a member of the police to remove a child without a warrant in circumstances where it is believed to be critically necessary for that child's protection. ${ }^{2}$ Section 40 provides for a warrant for removal to be issued following an application under s 67 of the Act. The POS warrant procedure exists in the middle of this hierarchy of removal powers, and each power should be considered in terms of the other methods for protection which are available.

The process under s 39 may be divided into three distinct stages. First there is the decision to make an application for a POS warrant by a social worker or member of the Police. $^{3}$ The section does not specify the standard of belief required by the applicant before an application may be made. ${ }^{4}$ It is arguable that the social worker's belief should at least of the same standard as that required of the person issuing the warrant. That would be a reasonable suspicion that the child is at risk of harm which would satisfy the threshold elements in s 39(1). The level of the applicant's belief is especially important given that the judicial officer is "necessarily obliged to rely on the [applicant's] assessment" 5 of the situation. Moreover, the social worker must ensure that in such an application a full statement of details is placed before the court to allow an informed decision to be made. ${ }^{6}$

It is also necessary that the applicant for a POS warrant critically assess the information which forms the basis of the concern for the child. ${ }^{7}$ This would include an evaluation of the credibility of persons supplying information. ${ }^{8}$ The need for a social worker to act responsibly in making such an application is accentuated by the fact that the

2 In B $v$ Director-General of Social Welfare [1991] NZFLR 288 Judge Inglis QC noted that this power should be invoked "only in the most exceptional and pressing circumstances". The section sets out the statutory test for the use of the power.

3 As the vast majority of applications are made by social workers, this discussion will identify a social worker as the applicant for a removal warrant. Any reference to a child should be taken as including a reference to a young person under the Act.

4 Section 39 only specifies the standard of belief required for the issuing of a warrant, and for the removal of a child.

5 Re a Child S (1991) 8 FRNZ 376, 381 per Judge Inglis QC. A number of social workers commented that the person issuing the warrant relies heavily on the advice of the applicant.

6 See DSW v M (1990) 6 FRNZ 593, 597; Re Children CYPF041/001/91 (1991) 7 FRNZ 472, 474.

7 For the possibility of a social worker being civilly liable to parents for a failure to conduct careful investigations, see the obiter statement of Morris J in $E v K$ [1995] 2 NZLR 239, 249-250.

8 See the criticism of a social worker for relying on information from a therapist whose credentials had not been verified in Re $a$ Child $S$, above $n 5,382$ per Judge Inglis $Q C$. 
application is made ex parte. ${ }^{9}$ The decision to make an application is in practice usually made in consultation with a supervising social worker and the approach to intervention may vary depending upon the office concerned. In general the POS warrant procedure is seen by social workers as being reserved for only very serious situations of risk.

The second stage in the POS procedure is the decision to issue a warrant under s 39(1). The warrant may be issued by a District Court Judge, or if no such Judge is available, by any Justice of the Peace or registrar. The s 39(1) test requires that the person issuing the warrant be satisfied that there are reasonable grounds for suspecting that a child is suffering, or is likely to suffer, ill-treatment, neglect, deprivation, abuse or harm. This is a lower threshold than is required for the decision to remove a child under s 39(3). ${ }^{10}$ As noted the judicial officer is likely to rely heavily on the applicant's assessment of the situation in deciding whether to issue a warrant. ${ }^{11}$

The third stage of the procedure is the execution of the warrant by the person so authorised. Section 39(3) makes provision for both entry and search of specified places, and for the removal of children in specified circumstances:

(3) Any person authorised by warrant under this section to search for any child or young person may-

(a) Enter and search, by force if necessary, any dwellinghouse, building, aircraft, ship, carriage, vehicle, premises or place:

(b) If that person believes, on reasonable grounds, that the child or young person has suffered, or is likely to suffer, ill-treatment, serious neglect, abuse, serious deprivation, or serious harm,-

(i) Remove or detain, by force if necessary, the child ...

For a child to be removed under a warrant the holder must have reasonable grounds for believing that the child has suffered, or is likely to suffer ill-treatment, serious neglect, abuse, serious deprivation or serious harm. ${ }^{12}$ The majority of Family and District Court

9 As to ex parte applications see the comments of Robertson J in C v K [1995] NZFLR 139, 143; and the criticism of the decision by M Henaghan in "Ex parte orders and the CYPF Act 1989" (1995) 1 BFLJ 183, 184.

10 In that case the person must hold a reasonable belief rather than a reasonable suspicion. Further, under s 39(3) the statutory grounds of neglect, deprivation and harm are qualified by the term "serious".

11 For a summary of relevant principles in the first two stages of the process see the decision of Judge Blaikie in DSW v M (1990) 6 FRNZ 593.

12 It is interesting that under $\mathrm{s} 39(1)$ the requirement is that the child "is suffering, or is likely to suffer", whereas s 39(3) requires that a child "has suffered, or is likely to suffer". 
decisions to date have focused on the first two stages of the POS procedure. In $R v$ Kahu the Court of Appeal had the opportunity to consider this final stage of the procedure. More particularly, the Court was asked to define the powers of search created by s 39(3).

\section{II $\quad R v K A H U$}

In Kahu a social worker, who had concerns regarding the young child of the appellant $(" K "),{ }^{13}$ visited the house earlier in the day. He received a hostile reception from a male present and smelt cannabis at the house. The social worker subsequently obtained a POS warrant, and returned to the house with a police officer. The male previously present had left the house, but $\mathrm{K}$ and her children were still present. The social worker explained to $\mathrm{K}$ that he had a right to enter the house, and to check the food situation and see the children. He also explained that he could remove the child named in the warrant if that was necessary. The police officer was in possession of a warrant under the Misuse of Drugs Act 1975 , but this warrant was not produced or relied upon. The social worker and police officer entered the house. The social worker checked the physical state of the children and asked if the police officer could look in the cupboards to check for the availability of food. The appellant $\mathrm{K}$ agreed to this and it was during this search that a small plate of cannabis was discovered. The social worker told $\mathrm{K}$ that she should "come clean" and this resulted in her revealing a substantial quantity of cannabis in the bedroom. $\mathrm{K}$ was then formally arrested and the child taken into custody under the POS warrant. $\mathrm{K}$ was convicted of being party to the possession by another of cannabis for the purposes of sale or offering for sale.

On appeal to the Court of Appeal it was argued that the cannabis should have been inadmissible as evidence against $\mathrm{K}$ as it was illegally obtained. On this basis $\mathrm{K}$ sought to have the conviction overturned. The case was not concerned with the granting of the POS warrant, but with the admissibility of evidence obtained through the exercise of it. Counsel for $\mathrm{K}$ argued that the social worker had acted beyond the scope of the authority under $\mathrm{s} 39$, and hence any evidence was obtained illegally.

The issue on appeal was identified by Richardson J as being: ${ }^{14}$

[W] hether the evidence of the finding of the cannabis in the bedroom on which the charge was based was obtained in breach of s 21 of the New Zealand Bill of Rights Act 1990 prohibiting unreasonable search and seizure.

In addressing this issue the Court focused on whether s 39(3) empowered the social worker to search only for the child, or to go further and search for the availability of food and other evidence relating to the condition of the child. The argument advanced by counsel

13 The nature of those concerns was not revealed in the judgment.

14 Above n 1, 4. 
for $\mathrm{K}$ was that the consent to the search of the cupboards could not be effective if the advice of the social worker was wrong in law. The Court was therefore required to consider the extent of the authorisation conferred on the social worker by s 39(3) of the Act.

\section{A The Majority Decision}

It is worth noting that this case concerned the admissibility of evidence in criminal proceedings. Section 39 was not considered from the perspective of child protection. Rather, the focus was on the ambit of the section to determine whether search powers had be legitimately exercised.

The majority of the Court of Appeal was unable to accept that s 39(3) authorised the search for a child and nothing further. Richardson J stated: ${ }^{15}$

In order to form the requisite belief the holder of the warrant must, we think, be entitled to exercise his or her best judgment on the information then available and be entitled to take positive steps to that end. Those steps may appropriately include checking on the apparent physical condition of the child, the conditions in which the child is living and the supply of food and other necessaries available for the child's well-being.

The Court held that these extended powers were implicit in the power to search, and the requirement that the person executing the warrant form an independent judgment as to whether or not the child should be removed or detained. The Court then impliedly conceded that the plain reading of the statute had been departed from in this interpretation of $s 39$. This was done in two ways. First the Court noted that the interpretation reflected: ${ }^{16}$

[T]he statutory mandate to the Courts under s 5(j) of the Acts Interpretation Act 1924 to adopt a purposive approach to the interpretation of the legislation so as to best ensure the attainment of the object of the provision according to true intent, meaning and spirit.

Secondly Richardson $\mathrm{J}$ held that in a case of deficient statutory drafting, the Court should favour an interpretation that will produce a workable result under the legislation.

It was concluded therefore that the holder of a warrant under s 39 may check the supplies of food and may open cupboards for that purpose. The Court at this point did not expressly deal with the New Zealand Bill of Rights Act, nor was it actually stated that the search was reasonable. The appeal against conviction was dismissed. 


\section{B The Dissenting Judgment}

In the sole dissenting judgment, McKay J strongly departed from the majority of the Court on the interpretation of $s$ 39. The Judge focused on the clear wording of the section and refused to imply in any extended powers of search. His Honour began by analysing subs (1) of s 39 and in terms of what a warrant actually authorises, noted: "If it was intended to authorise a search of the house for evidence, ... then the wording of the section is surprisingly inapt to convey such an intention."17

The Judge then considered subs (3) of s 39 and concluded that nowhere in the section is there any express power to search the house for evidence that a child has been ill-treated or neglected. In conclusion, McKay J held that the need for such an extended power of search is not so obvious that it should be inferred in the absence of express provision and stated further: ${ }^{18}$

The section is reasonably detailed, and it forms part of a very long and detailed statute. If it was intended that the warrant should include authority to search for evidence, then it is surprising that the section not only does not say so, but expressly refers only to authority to search for the child or young person.

The Judge held that the advice given to $K$ was wrong in law, and hence the search of the cupboard was unauthorised. In conclusion McKay J differed from the majority of the Court on the extent of the authorisation conferred by $s 39$, and stated that he would allow the appeal.

\section{An Analysis of the Decision}

The POS procedure has been described as draconian and invasive. ${ }^{19}$ This was prior to the decision in Kahu. The majority decision in that case certainly does not mitigate the intrusive nature of the warrant power, rather it constitutes a widening of the powers of intrusion. The differing approaches in the Court of Appeal in this case are clear. The majority held that the section was inadequate to achieve the ends intended, and hence an implied power of further search was interpreted in to produce a workable result. In contrast McKay J held that the words of the section were clear in that it authorises only a search for a child and that the implied power was neither necessary nor justifiable.

It is arguable that, in a situation where the Court is dealing with a power that encroaches on the liberties of individuals, it should be less inclined to depart from a clearly

17 Above n 1, 6.

18 Above n 1, 7.

19 See Re Children above n 6; Re M [1990] NZFLR 575. 
defined statutory authority. ${ }^{20}$ Conversely it is clear that, in the context of the CYPF Act, the legislation should be interpreted so as to ensure the welfare of the child.

Henaghan has stated: 21

The function of legislation and its interpretation is to provide answers, and an authoritative settlement of the problem ... Ultimately the Judge must be guided by which argument best fits the statutory wording. That wording is the crucial democratic limit on what could otherwise be the arbitrary exercise of power - no matter how "fair and reasonable" the Judges may think they are being. Interpretations which seem to reach unfair results can be challenged on appeal or by a legislative change of the wording.

Similarly Hayes has commented: ${ }^{22}$.

Child care law must seek to avoid the pitfalls which are the hallmarks of all legislation: too precise drafting may inadvertently create loopholes; too loose drafting may permit intervention where there are insufficient reasons for it; for the courts must seek properly to interpret the will of Parliament and are not entitled to rewrite ill-written Acts.

The majority of the Court in Kahu was prepared to depart from what is arguably a clearly worded piece of legislation in an attempt to achieve a workable result.

\section{The workable result}

In analysing the decision in Kahu, it is useful to examine the conclusion by the majority of the Court that the plain reading of the section does not produce a workable result, and that the extended powers of search do achieve this end. It has been noted that $\mathbf{s} 39$ is prima facie clear in its directive that the search authorised is a search for a child, and not a search for evidence. McKay J held that this was evident in both subss (1) and (3) of s 39.

The majority of the Court was not prepared to accept such a straightforward interpretation, and this was arguably due to the mechanics of the two step test under $\mathrm{s} 39$. The Court noted the higher standard of belief required under subs (3), and questioned how this belief could be achieved without some extended powers of search. It was held that in order to form that requisite belief the social worker should be able: "[T]o take positive steps to that end." 23 Those steps would go beyond searching for the child, and extend to checking the supply of food and other necessaries.

20 This would accord with the statutory directive under $\mathrm{s} 6$ of the New Zealand Bill of Rights Act 1990.

21 M Henaghan, Editorial, "Family Law and its Interpretation" (1994) 1 BFLJ 130.

22 M Hayes "Child Protection in New Zealand and England" (1986) 3 Canta LR 53, 56.

23 Above $n 1,6$. 
This approach is interesting in that it makes two important assumptions. The first is that the social worker will not have the requisite belief at the time of application. One approach to the interpretation of $\mathbf{s} 39$ is to assume that upon application the social worker will only possess a reasonable suspicion of the risk of harm. Once the warrant is issued that person will proceed to search for the child. The child is then located and the social worker looks for evidence that will elevate the reasonable suspicion into a reasonable belief. It is submitted that the core of the majority decision in Kahu was based on this progression. The extended powers of search were required to achieve a level of belief not previously held.

It is possible, however, to interpret $\mathbf{s} 39$ in a different manner. This alternative approach focuses on the element of time constraints. It is arguable that the lower level of belief required by the judicial officer issuing the warrant under $\mathbf{s} 39(1)$ is intended to reduce the time expended at this stage. It could be that Parliament did not require a social worker to persuade the judicial officer to the level of reasonable belief due to the time constraints involved. A higher level of belief on the part of the person issuing the warrant would involve a more extensive evidential process and the consequent delays. This argument also recognises the fact that, in reality, the person issuing the warrant will to a large extent rely on the applicant's assessment of the situation. It is arguable therefore, that the two step test in $s 39$ is a reflection of a leysslative desire to reduce unnecessary delays in the issuing of warrants in this type of urgent situation. It does not necessarily reflect that a lower level of belief will be held by the social worker at the time of application. ${ }^{24}$

That the majority took the view that a social worker is unlikely to have a higher belief prior to executing the warrant is evidenced by statements such as: "and if, and only if, that person forms the belief on reasonable grounds ... remove or detain the child..." 25 This approach was arguably a result of the Court focusing on the former of the two approaches to the dual tests in s $39 .{ }^{26}$ One social worker commented that the belief will, in most cases, be formed prior to the execution of the warrant. If this is not the case, general observations at the time of the search will confirm or remove any suspicion held.

The second assumption inherent in the reasoning of the majority of the Court is that the power to search for evidence will in fact render a non-workable section workable. In the dissenting judgment McKay J stated that the section did not require an extended power for it to be workable. The Judge noted: ${ }^{27}$

24 See the comments of McKay J at above $n$ 1, 7.

Above n 1, 5.

That approach being that the two step test is designed to allow a social worker to attain a reasonable belief which was not previously held. 
In most cases evidence will already be in the possession of the department before a warrant is obtained, possibly in the form of information from neighbours, or from professionals who were aware of the situation.

The Judge did accept that in some cases there will be less than a reasonable belief prior to the execution of the warrant. This could be overcome, however, by observing the appearance of the child, the attitude of the parent, or other matters at the time of the search. ${ }^{28}$ Whether the section is workable without the extended powers of search is arguably best answered by reference to the professionals working under the legislation. The first point to note is that the section has been in use in its present form since the Act came into force. ${ }^{29}$ It is submitted that it would be strange if the section was unworkable, yet the Children and Young Persons Service has not sought to have it amended. It is clear that some social workers, as was the case in Kahu, have proceeded under the assumption that the extended powers were implicit in the section. The consensus from the social workers interviewed, however, was that the extended powers were not provided for under the section. All of the social workers interviewed were surprised that this extended power was regarded by the Court as being both implicit in s 39 , and necessary to render the procedure workable. The general opinion was that the section was definitely workable without the extended powers of search, and one supervising social worker commented that s 39: "...is a very clear piece of legislation."

It is submitted that the extended powers of search conferred by the Court may not in fact render the POS warrant power any more workable than it was. If for example, as was the case in the Kahu scenario, the concern was whether there was food available for the child, then a search of the cupboards in itself will not be conclusive proof of this. McKay J noted that: "the mere absence of food is unlikely of itself to be determinative." 30 The search may be conducted just prior to the day on which the household normally purchases food. This may reveal very low levels of food. Similarly, the child may survive mainly on "fast food" which would result in the cupboards being empty, but not necessarily in the child being neglected.

The best evidence in the POS scenario may in fact be the child itself. ${ }^{31}$ The observation of the child, the answers to questions asked, and an observation of the general surroundings may be the most reliable way that a social worker can supplement any information already obtained. One supervising social worker commented that in practice the social worker will

28 Above $n$ 1, 7.

29 The warrant power also existed in a very similar form under s 7 of the Children and Young Persons Act 1974.

30 Above $n$ 1, 7.

31 This view was held by McKay J, above n 1, 7. 
sit down and discuss the concerns with the family. The observations of the child, the relationship between the parent(s) and child, the general atmosphere and any comments made will normally be more than sufficient to form a view as to whether removal is necessary.

It is respectfully submitted that the POS warrant procedure is workable without an implied authority to search for evidence. This is clear from the comments of those who actually use the warrant. The words of $s 39$ are reasonably clear, and the marginal benefits of these extended powers of search do not justify a clear statutory directive being ignored. The POS warrant is an inherently intrusive power which should be stringently limited to the ambit of the words that create it.

\section{The Bill of Rights perspective}

The Court in Kahu did not consider the application of the New Zealand Bill of Rights Act 1990 ("BORA") in any detail. This is interesting given that the issue on appeal was described by the Court as whether s 21 of the Act had been breached. Section 21 of the BORA relates to unreasonable search and seizure:

21. Unreasonable Search and Seizure- Everyone has the right to be secure against unreasonable search or seizure, whether of the person, property, or correspondence, or otherwise.

The Court did not actually discuss s 21, or conclude that the search conducted by the social worker was reasonable. Rather, the focus was on the legality of the search. This was determined by the extent of the authorisation afforded under s 39(3). Once this legality was established, the appeal was dismissed.

This approach by the majority is interesting in that it considers the legality of the search under s 39, and the reasonableness of the later action taken by the social worker in asking $\mathrm{K}$ to come clean. The Court did not consider whether the search of the cupboards was reasonable in terms of $s 21$, but rather relied purely on the finding that it was legal.

The distinction between legality and reasonableness was considered by the Court of Appeal in $R v$ Jefferies ${ }^{32}$ where the majority was of the opinion that legality was not determinative in a decision as to reasonableness: "Illegality is not a touchstone under $\mathbf{s}$ $21 " .33$

32 [1994] 1 NZLR 290.

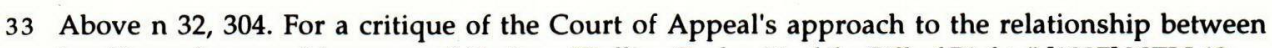
legality and reasonableness see S Optican "Rolling Back s 21 of the Bill of Rights" [1997] NZLJ 42. 


\section{THE LIMITS ON THE POWERS OF SEARCH - POST KAHU}

The Court of Appeal has made a clear statement in Kahu that the power of search under $\mathrm{s}$ 39 is not restricted to the power of search for a child. It is therefore worthwhile considering the ambit and limits of these extended powers of search in the light of the Kahu decision.

The first extension to the power was accepted both by counsel for K, and by McKay J in the dissenting judgment. The Court noted that counsel for $\mathrm{K}$ "was inclined to accept that the statutory authority might extend to physically inspecting the child for signs of neglect or to observing the physical conditions in which the child was living." ${ }^{34}$ McKay J held that: "The appearance of the child, or the attitude of the parent, or other matters observed at the time of the search may all be taken into account." 35

The majority of the Court then extended the power of search to include "checking ... the supply of food and other necessaries available for the child's well-being." 36 It was this extension of the powers of search which was not accepted by McKay J.

The test therefore is that the person executing the warrant may search for the child, observe the surroundings in which the child lives, physically inspect the child, ${ }^{37}$ and search for the supply of food and other necessaries available for the child's well-being. It is interesting to consider whether, in using the term "necessaries", the Court was intending to draw an analogy with the term as used in s 151 of the Crimes Act $1961 .^{38}$ In that context necessaries have been held to include food, clothing, and medical attention. ${ }^{39}$ The decisions under s 151 may prove useful in formulating an interpretation of that term as used by the Court in Kahu. It is submitted however that the s 39 power has not been extended to a general power to search for the availability of necessaries. Rather, arguably a social worker may only search for necessaries when the availability or non-availability of them will directly establish, or otherwise, one of the grounds for removal under s 39 . The threshold test for removal is found in the section and not under the broader head of lack of necessaries. Therefore while a lack of sufficient clothing for a child may evidence a lack of necessaries, this would not automatically establish a ground for removal under $\mathrm{s} 39$.

34 Above n 1, 5.

35 Above $n 1,7$.

36 Above $n 1,6$.

37 While the majority of the Court of Appeal states that the social worker may physically inspect the child, McKay J refers only to: "The appearance of the child ..." and to the fact that: "The child may show signs of malnutrition or ill treatment". See above $n 1,7$.

38 This section creates a duty to provide the "necessaries of life."

39 For a discussion of medical attention see $R v$ Moore [1954] NZLR 893, $R v$ Burney [1958] NZLR 745. 
The POS warrant could potentially be used as a tool to facilitate an investigation rather than as a method to ensure the protection of a child. Jefferson and Laven have noted that this is particularly so when the family is perceived as uncooperative. They go on to state: "Plainly, unless implementation of the procedures can be justified on the basis of there being no other means of protecting the child, this would be an abuse of process." 40 In this context an interesting analogy may be drawn between the extended powers of search in the POS context, and the decision of the Court of Appeal in Television New Zealand $v$ AttorneyGeneral. ${ }^{41}$ That case related to the execution of a search warrant in respect of video recordings held at the premises of Television New Zealand. In considering the exercise of this power, Cooke $\mathrm{P}$ (as he then was) made a number of observations relating to the use of warrants generally. His Honour noted that warrants were to be read as a whole and stated: $:^{42}$

The wide words ... from the prescribed form and the warrant should not be read as authorising a roving or "fishing" search of the premises ... Warrants have to be executed having regard to their purpose ...

These comments support the proposition that limits do exist to the extended powers of search under Kahu. A social worker could not use the POS warrant to conduct a "fishing expedition." Similarly it would be inappropriate for a member of the police to use the warrant as a means of searching for evidence of the commission of a crime.

Another limit to these extended powers of search is that, once the reasonable belief is formed, any further powers of search should be extinguished. This limitation comes from the Kahu decision itself. The Court, in justifying the extended powers, noted: "In order to form the requisite belief the holder of the warrant must ... be entitled to take positive steps to that end." 43 These words indicate that the extended powers are implied into the section only to assist the formation of the belief, and not in a more general sense. In the Kahu scenario therefore, if the cupboards were searched after the requisite belief was formed, this search would have been unlawful.

\section{THE LIMITS ON THE POWERS OF SEARCH IN PRACTICE}

It is useful to examine some hypothetical situations, in an attempt to define the outer limits which apply to the extended powers of search identified in Kahu.

40 S Jefferson and R Laven The Care and Protection Provisions of the Children, Young Persons and Their Families Act 1989 Revisited (New Zealand Law Society Seminar Paper, August 1995) 21.

41 [1995] 2 NZLR 641.

42 Above n 41, 646.

43 Above n 1, 5-6. 


\section{A The Front Lawn}

One interesting issue is whether the powers of search may be exercised in a house in which the child has not been located. The child may, for example, be located on the front lawn. The question to be asked is whether the social worker has the authority to enter and search the house to determine the availability of necessaries. This scenario would arguably be encompassed within the broad test in Kahu. That test allows a social worker, having located the child, to take further positive steps towards forming the belief required. Those steps would arguably include, in this scenario, entering and searching the house. ${ }^{44}$

\section{B The School Scenario}

Similarly it is quite common for a child to be located and removed under a warrant while attending school. If the child is actually removed from or detained at school, then the belief must have been formed by that time. If, however, the child is located at school but the social worker does not hold the requisite belief, it is questionable how the powers of search operate. Under the Kahu ruling the power would extend to the searching of the child's bag for adequate food and clothing. The issue is whether the social worker may then proceed to the child's home to search for the availability of necessaries. This scenario was clearly not envisaged by the majority of the Court in Kahu. ${ }^{45}$ That case involved a situation where the social worker was already in the house. As noted in the above example, the powers may extend to a situation where the child is located in the vicinity of the house. It is however arguable that the extended powers of search do not create fresh powers of entry as would be required in this example. It is submitted that this would be an unreasonable extension of the Kahu rule.

The Public and Administrative Law Reform Committee noted that a power to enter should be conferred expressly and not by implication, ${ }^{46}$ and stated further: "In our opinion the conferring of a power to enter private property is too great an infringement of private rights to be done by implication". ${ }^{47}$

44 As noted, this action would be justified only if the social worker had not, at that point, formed the belief.

45 McKay J did note that if s 39 was intended to authorise the search of a house for evidence: "... even in circumstances where the child was found elsewhere, then ... the section is surprisingly inapt to convey such an intention." Above n 1, 6 .

46 Public and Administrative Law Reform Committee Statutory Powers of Entry (Report No 17, Wellington, 1983) 6.

47 Above $n$ 46,6. The Committee did not consider the powers of search. However it is arguable that this comment should apply equally to powers of search and powers of entry. This accords with the approach of McKay J to the powers of search in Kahu. 
It is therefore necessary to consider how the wording of $s 39$ applies to this right of further entry in this example. It is submitted that $s$ 39(3) can be read in two ways. The first possible interpretation is that under s 39(3), the power of entry ${ }^{48}$ exists only up to the point at which the child is found. This is not entirely clear from the wording of the subsection:

(3) Any person authorised by warrant under this section to search for any child or young person may -

(a) Enter and search, ...

(b) If that person believes, on reasonable grounds, ... remove the child ...

It could be argued that, as the person is authorised to search for any child, the powers of entry exist only in respect of the search for the child. The rights of entry therefore would be extinguished upon the child being located. ${ }^{49}$ This interpretation would suggest that while the social worker could search the school for evidence of neglect, the power would not extend to the subsequent entry and search of the child's home.

The alternative interpretation is that subs (3) allows for entry and search of any specified place in order to form the requisite belief, and that this power exists independently of the child being located. This interpretation would be based on the argument that, although reference is made in subs (3) to the search for any child, para (a) of that subsection does not actually specify that the entry and subsequent search must be for that child. It could be argued that, once a person is authorised by the section to search for any child, then there exists a power under subs (3)(a) to enter and search any place in order to form the belief required under para (b). This power would therefore exist regardless of where the child is located, and at any time before or after the child is located. ${ }^{50}$ This interpretation would allow the social worker, after having located the child at the school, to proceed to the child's house to search for the availability of necessaries.

It is submitted that the first of the two possible interpretations is more in line with the intention of the section. This is, however, open to argument. There are no indications in the judgment that the latter alternative was argued before the Court in Kahu.

48 Note that the Court of Appeal arguably extended only the powers of search, not the powers of entry.

49 The powers of search would continue at this point under the Kahu rule.

50 This interpretation would arguably have been another way in which the Court of Appeal could have reached the desired result in Kahu. Under this interpretation the Court could have relied on the wording of the section, rather than resorting to an implied power. This would have resulted in the powers of search (and entry) being extended. 


\section{The Child in Hospital}

The preceding analysis may also apply to the situation where a child is in hospital. Under s 39(3)(b)(ii) where a person executing a POS warrant locates a child in a hospital, that person may, upon forming the requisite belief, direct that the child be kept in the hospital. If in this situation the social worker had formed the belief required and directed that the child be kept in the hospital, then arguably any further power of search would be extinguished. If, however, the requisite belief was not formed, the social worker may wish to search the child's house for that purpose. The analysis conducted in the above examples is equally applicable here.

Another interesting question is whether the social worker would have the power to search the hospital for evidence of harm or neglect. This evidence may be found in the records of the patient, which the social worker may demand to see under the rights conferred in Kahu. The social worker may wish to search for medical evidence of illtreatment, neglect, abuse, deprivation or harm. This creates a conflict between the child's right to confidentiality, and the powers under the POS warrant. The social worker could apply to the Court for an order that the child be medically examined. ${ }^{51}$ However that person may prefer to rely on the search powers under the POS warrant to obtain the records of examinations already conducted.

It is possible that the social worker may have this power under the Kahu ruling. Where the child is found in a house, the Court has allowed a further search power that constitutes an intrusion into the family's right to privacy. Arguably, the Court may permit an intrusion into the doctrine of patient confidentiality to allow records to be searched in urgent circumstances.

\section{The Missing Child}

The situation may arise where a social worker attends a house but discovers the child is not present. The social worker may then wish to search the house to confirm or deny any suspicion held. It is arguable that the extended powers of search may be exercised only after the child is located. The Court in Kahu noted that the extended power to search: $\mathbf{5 2}$

is implicit in the authority to search and the requirement that, having located the child, the person executing the warrant form an independent judgment as to whether or not the child should be removed or detained.

51 Ss $49-58$ of the Act.

52 Above n 1, 6. 
This statement suggests that the child must be located before the Court would allow the extended powers of search to operate.

\section{E Summary}

These examples have attempted to explore the boundaries of the POS warrant powers as interpreted by the Court of Appeal. The decision in Kahu was based on what might be described as the orthodox POS scenario, that is, where the child is found in a house, and the social worker is then empowered to search further for evidence. There are limits, which have been discussed, even in this orthodox situation. The less orthodox situations discussed attempt to test the outer limits of the Kahu rule.

\section{CONCLUSION}

The importance of the POS procedure for child protection cannot be overstated. The vulnerable position of the child within the family necessitates removal in situations of unacceptable risk. This principle must be paramount. The Act also recognises the right of the family to be free from unreasonable interference. The Court in Kahu extended the powers of search under s 39 to include the power to search for evidence of harm. As noted, this interpretation is at odds with a clearly worded piece of legislation, and is arguably unnecessary to achieve a workable result. The limits which do apply to the use of this extended power are not entirely clear, but they should be carefully considered by those who exercise authority under the section. 